\title{
Winship Cancer Institute
}

National Cancer Institute

\section{Source}

National Cancer Institute. Winship Cancer Institute. NCI Thesaurus. Code C105630.

Winship Cancer Institute is dedicated to the integ ration of innovative clinical and basic science research with patient care for the prevention, treatment, and control of cancer. It became an NCl-designated cancer center in 2009. It is a component of the Robert W. Woodruff Health Sciences Center of Emory University. 